\title{
Últimos descubrimientos en la tumba saíta no 14 del yacimiento arqueológico de Oxirrinco (el-Bahnasa): la cámara funeraria no 6
}

\author{
Esther PONS MELLADO
}

La habitación $n^{\circ} 6$ de la tumba saíta $n^{\circ} 14$ del Yacimiento Arqueológico de Oxirrinco (El- Bahnasa), Egipto, es, sin lugar a duda, una de las más interesantes tanto a nivel arqueológico como histórico. La gran cantidad de objetos de ajuar funerario hallados en ella: vasos canopos epigráficos, ushebtis, jarras de cerámica, restos de pan de oro, de cartonaje y del sarcófago de madera, cientos de canutillos y cuentas de collar, así como diversos amuletos, evidencian una estancia destinada a alguien importante dentro de la comunidad saíta de Per-Medyed.

Latest discoveries in Saite tomb $n^{\circ} 14$ of the archaeological site of Oxyrhynchus (el-Bahnasa): funerary chamber $n^{\circ} 6$

Room $n^{\circ} 6$ of the tomb $n^{\circ} 14$ of the Archaeological Site of Oxyrhynchus (El-Bahnasa), Egypt, is one of the most interesting in both archaeological and historical terms. The great quantity of funerary objects found: stone canopic jars, ushabtis, clay pottery, the remains of goldleaf, cartonnage and a wooden coffin, hundreds of necklace beads, together with several amulets, prove that this is a chamber destined for an important person within the Saite community of Per-Medjed.

KEY wORDs: Oxyrhynchus, 26th Dynasty

$\mathrm{E}$ 1 yacimiento arqueológico de Oxirrinco (ElBahnasa), la antigua Per-Medyed, se encuentra situado a unos $180 \mathrm{~km}$ al sur de El Cairo, en la provincia de Minia. Fue la capital del Nomo XIX del Alto Egipto y su importancia vino determinada en gran medida por su emplazamiento geográfico, que lo situaba en una de las principales vías de acceso a los oasis del desierto occidental, y por las ventajas de un puerto fluvial en el Bahr Yusef, un brazo del Nilo.

Las primeras noticias de época moderna que tenemos de este yacimiento nos vienen de la mano de

Vivant Denon ${ }^{1}$, miembro de la Expedición Científica de Napoleón Bonaparte de 1789, que publicó algunos grabados sobre la arquitectura antigua de Oxirrinco. Entre ellos hay que destacar una enorme columna dedicada a Focas, emperador del Imperio de Oriente.

A finales del siglo XIX, dos jóvenes ingleses del Queen's College de Oxford, Bernand P. Grenfell y Arthur S. Hunt no sólo descubrieron un vertedero con miles de papiros ${ }^{2}$, escritos en la gran mayoría en griego, y en menor medida en latín, copto y

1. Denon, 1802: 90, lám. 31.

2. La gran mayoría de papiros se hallaron entre 1902 y 1903 y hoy en día se encuentran en el Ashmolean Museum de Oxford.

Fecha de recepción: 10 de febrero de 2007

Fecha de aceptación: 25 de junio de 2007 
árabe, sino que también llevaron a cabo un estudio arqueológico de la zona, levantando planos de las tumbas del Imperio Nuevo, Época Ptolemaica y Época Romana. Trabajaron entre 1897 y 1907. Los dibujos definitivos de estos planos fueron publicados por Darbishire en 1908, inspirándose en los croquis de los dos papirólogos ${ }^{3}$.

Unos años más tarde y hasta 1913 un equipo italiano dirigido por Ermenegildo Pistelli continuó excavando en esta área encontrando numerosos papiros.

A partir de la Primera Guerra Mundial, como consecuencia de la construcción del ferrocarril, comenzaron a realizarse los primeros saqueos en Oxirrinco, hasta que a comienzos de los años veinte arqueólogos como W.M.F. Petrie ${ }^{4}$ y E. Breccia ${ }^{5}$, iniciaron diversos trabajos cuyo fin era salvaguardar el importante patrimonio histórico de esta zona.

En 1982, el entonces Servicio de Antigüedades de Egipto, comenzó a dirigir las excavaciones de este yacimiento. Diez años más tarde se constituyó una Misión Mixta integrada por esta institución y la Universitat de Barcelona.

Desde entonces se está trabajando en dos grandes sectores: a) La necrópolis noroccidental que cubre un amplio marco cronológico que va desde época saíta hasta época bizantina y b) el santuarionecrópolis destinado al dios Osiris de Época Ptolemaica ${ }^{6}$.
En los años 1996 y 1998 se llevaron a cabo en la necrópolis noroccidental diversas prospecciones electromagnéticas que determinaron alteraciones en una zona del terreno, la cual comenzó a excavarse en el año 2002. Es en este lugar donde se ha encontrado la tumba $n^{\circ} 14$.

Se trata de una construcción funeraria de época saíta (dinastía XXVI) de grandes dimensiones ${ }^{7}$, con un total de once habitaciones, siendo la cámara funeraria $n^{\circ} 6$, sin duda alguna, una de las más interesantes, tanto a nivel arqueológico como histórico. Además, cuando se encontró estaba prácticamente intacta (fig. 1).

Dicha cámara fue hallada en la campaña del año 2005, a finales de noviembre, y está situada en el lado suroeste de la tumba, junto a la $n^{\circ} 5$, descubierta también durante esa misma campaña, pero que al contrario de la habitación $n^{\circ} 6$, se encontró muy destruida, y en su interior únicamente había un sarcófago antropomorfo bastante destrozado y diversos amuletos así como una lámina de oro representando un Nudo de Isis. Ambas estancias están separadas entre sí por un pasillo de losas de piedra. Arquitectónicamente es una habitación abovedada -igual que la $\mathrm{n}^{\mathrm{o}} 5$ que mide $1.70 \mathrm{~m}$ de altura $\mathrm{x} 1.96 \mathrm{~m}$ de anchura $\mathrm{y}$ $3.67 \mathrm{~m}$ de longitud. Está construida con grandes bloques rectangulares de piedra caliza, bastante bien tallados y pulidos, sin decoración alguna en sus paredes, y con la entrada por el lado sur con respecto a la tumba (fig. 2).

3. Darbishire, 1908: 13-17; Reeves, 2001: 107-108.

4. Petrie, 1925: 12-18, lám. 35-47.

5. Breccia, 1940: 104-116. los trabajos los realizó entre 1927 y 1934. Los papiros que encontró se encuentran en Florencia.

6. Padró et alii, 1993a; Padró et alii, 1993b; Padró et alii, 1996; Padró et alii, 2002; Padró et alii, 2004; Padró et alii, 2005; Padró, 2004.

7. Durante los dos primeros años de trabajo se extrajeron de esta zona una gran cantidad de bloques de piedra caliza de forma rectangular, que nos hicieron pensar que en su momento debió de ser una estructura de gran envergadura, tal y como al final ha resultado ser. También, y a medida que íbamos bajando, nos encontramos con numerosos fragmentos de tapas y cajas de sarcófagos de piedra de época saíta, que al igual que los bloques de piedra, estaban caídos y removidos. 


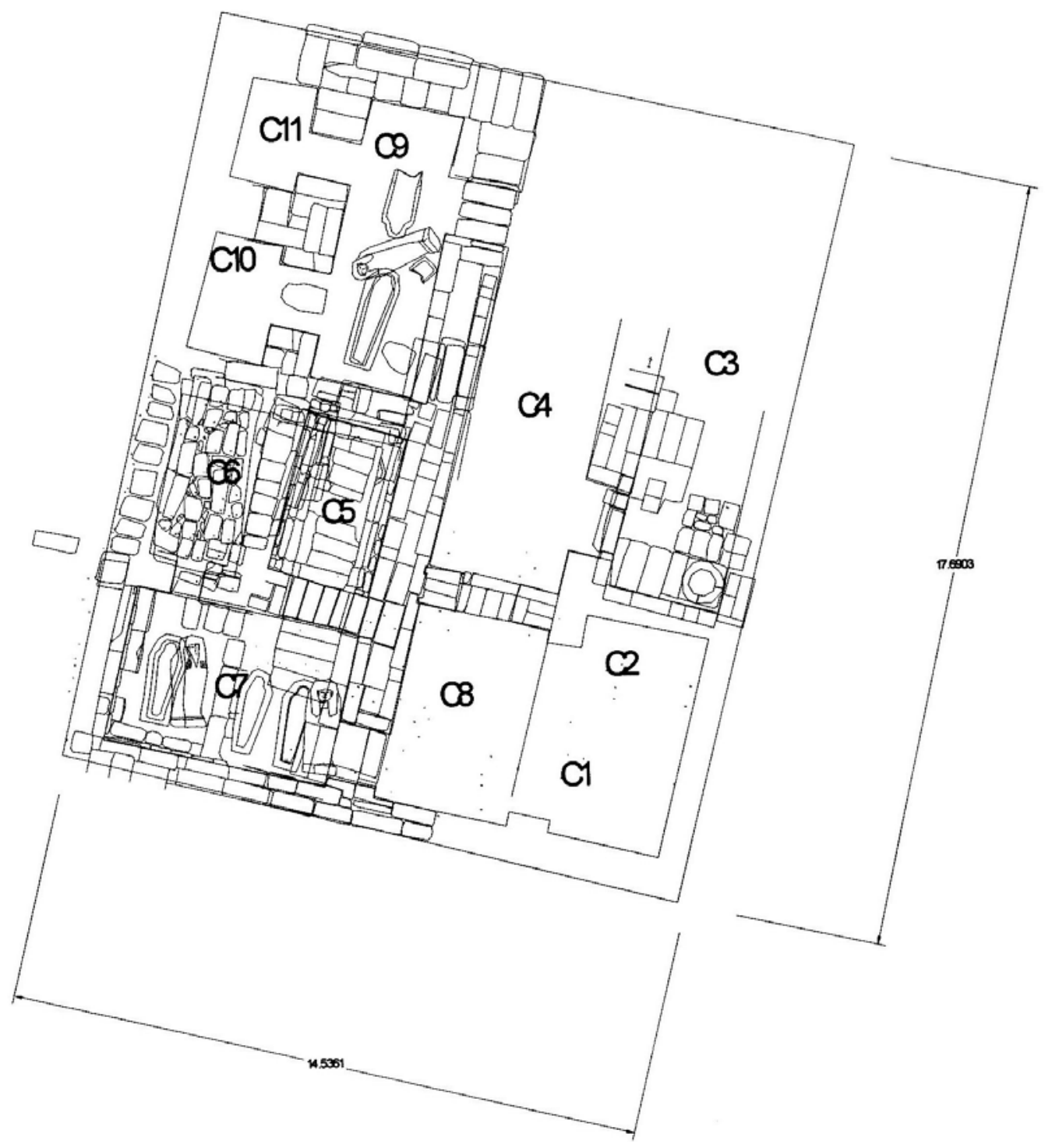

Figura 1. Planta de la tumba saita $n^{\circ} 14$

A medida que se iba excavando pudimos comprobar que el techo tenía al menos cuatro niveles de construcción, todos ellos realizados en la misma época. Para poder entrar en la cámara los saqueadores extrajeron algunos bloques de piedra de la parte superior de la entrada -que estaba rematada por un dintel-, con lo que consiguieron un orificio de unos $60 \mathrm{~cm}$ de anchura y no más de $40 \mathrm{~cm}$ de alto. Es por este hueco por donde también nosotros accedimos a la habitación.

En su interior, se encontraron diversos objetos pertenecientes al ajuar funerario: vasos canopos, ushebtis, amuletos, canutillos y

8. En esta zona se encontró un vaso canopo que todavía estaba cerrado con la tapadera, aunque más tarde se comprobó que ambas piezas no se correspondían. 


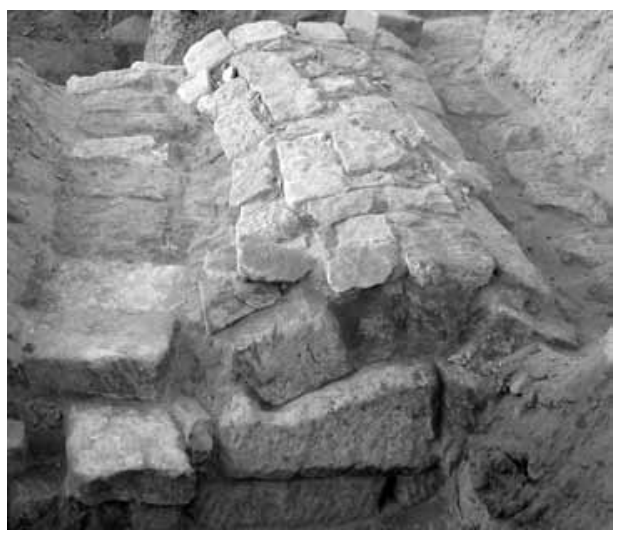

Figura 2. Exterior de la cámara $n^{\circ} 6$

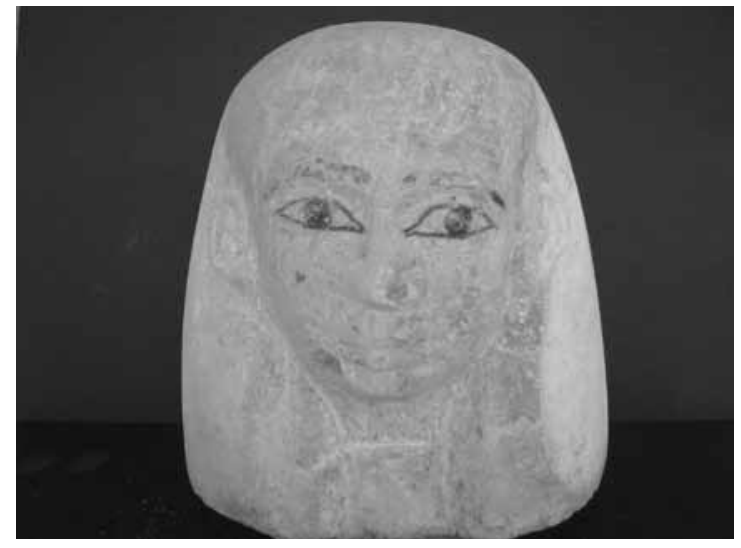

Figura 4. Tapadera de vaso canopo representando a Amset

El primer grupo de cuatro vasos canopos, el mejor tallado y conservado, presenta, en cada uno de ellos, una inscripción incisa a base de cinco líneas verticales paralelas, pintadas en negro -en algunas zonas el color se había perdido-, que hacen referencia a la figura de una mujer llamada Tadiher, hija de un profeta de Amón y profeta de Osiris, llamado Horisenef y de una mujer llamada Hepeset. Como es propio de las mujeres de Época Saíta carecía de título, aunque sí aparece la alusión "Tadiher, Señora de la Casa". La parte superior del borde de estos vasos lleva inscrito un dibujo de las cabezas de los dioses a los que representan dichos vasos canopos.

Los canopos del segundo grupo tienen también una inscripción incisa pintada en negro, pero en este caso a base de dos líneas verticales paralelas, y aunque su estado de conservación es bastante malo, se puede leer la alusión que hace a un nombre masculino, "Padineith, sacerdote de...".

Durante esta campaña no fue posible establecer la relación que había entre ambos nombres, ni por qué esta cámara contenía ocho vasos canopos a pesar de que tan sólo se encontró un cuerpo en su interior. Tendríamos que esperar, como veremos más adelante, a la campaña del año 2006

Figura 3. Interior de la cámara $n^{\circ} 6$ 
para establecer dicha relación y poder entender la presencia de estos dos conjuntos de recipientes funerarios.

Los ushebtis, todos en fayenza en color verde y turquesa, fueron descubiertos casi en su totalidad a lo largo del muro norte, aunque también se hallaron algunos esparcidos por la cámara. Se localizaron unos cuatrocientos de los que únicamente doce son epigráficos, llevando el nombre de Tadiher en el dorso. Las características físicas de estas figuras son las propias de los de Época Saíta. La gran mayoría son de pequeño tamaño, entre 5 y 7 $\mathrm{cm}$ de altura, con los rasgos faciales y corporales poco diferenciados. También se encontraron unos cuarenta ejemplares de mayor tamaño, entre $10 \mathrm{y}$ $12 \mathrm{~cm}$ de altura, mejor trabajados y con pilar en el dorso. A este grupo pertenecen las figuras inscritas antes mencionadas.

Este tipo de ushebtis han sido hallados en diversas habitaciones de la tumba 14 , como la $\mathrm{n}^{\circ} 2$, en donde había un sarcófago antropomorfo in situ, con la tapadera levantada y en cuyo interior se encontró una momia perteneciente a una mujer, con numerosos amuletos, canutillos y cuentas de collar, y ushebtis anepigráficos, tanto en el interior del sarcófago como en sus alrededores; la $\mathrm{n}^{\mathrm{o}}$ 7 y 8 , en donde, junto a los sarcófagos antropomorfos localizados en ellas, cuatro de ellos in situ (de los que tres tenían momia en su interior), se han hallado, no sólo amuletos, cuentas de collar y canutillos, sino también numerosos ushebtis de fayenza en color verde de características similares a los descubiertos en la cámara $n^{\circ} 6$.

En la esquina sur-oeste de esta cámara se encontró una gran jarra completa de cerámica de aspecto piriforme, y de unos $54 \mathrm{~cm}$ de altura, de pasta y superficie color rojizo. En la esquina noroeste se hallaron numerosos fragmentos de otra jarra de cerámica de pasta y superficie color rojizo, aunque de aspecto globular.
A tenor de la gran cantidad de canutillos y cuentas de collar descubiertas en esta cámara, el cuerpo de Tadiher debió de estar adornado con una malla de color azul, verde y dorado.

En cuanto a los amuletos, éstos no son muy numerosos, aunque hay que destacar una pequeña lámina de oro en forma de corazón $i b$ de $1.2 \mathrm{~cm}$ de anchura, otro corazón ib de piedra en color negro, y la figura del dios Horus-halcón en actitud de andar, de muy buena factura, realizado en lapislázuli.

Durante el estudio de la momia se pudo comprobar que todavía conservaba el escarabeo de corazón de unos $5 \mathrm{~cm}$ de longitud. Se trata de un ejemplar anepigráfico de piedra, de color verde oscuro, de muy buena factura y con los rasgos muy bien delimitados y marcados.

También se encontraron abundantes restos de cartonaje en vivos colores: azul, rojo, verde, negro, blanco, con una decoración vegetal y floral, que evidenciaban la belleza de éste, así como numerosos restos de pan de oro que muy posiblemente cubrían el sarcófago de madera que por desgracia nos ha llegado prácticamente destrozado.

En la esquina sur-oeste de la cámara encontramos ocho piezas de bronce que correspondían a los engarces del ataúd de madera.

Aunque durante la campaña 2005 pudimos limpiar por completo el suelo del interior de la cámara $n^{\circ} 6$ (fig. 5), comprobando que se trataba de un enlosado de piedra machacada, tuvimos que dejar para la siguiente campaña la limpieza de la zona exterior, frente a la puerta de entrada de esta habitación.

Durante la campaña de 2006 y al limpiar este área nos encontramos con una habitación ${ }^{9}$ cons- 


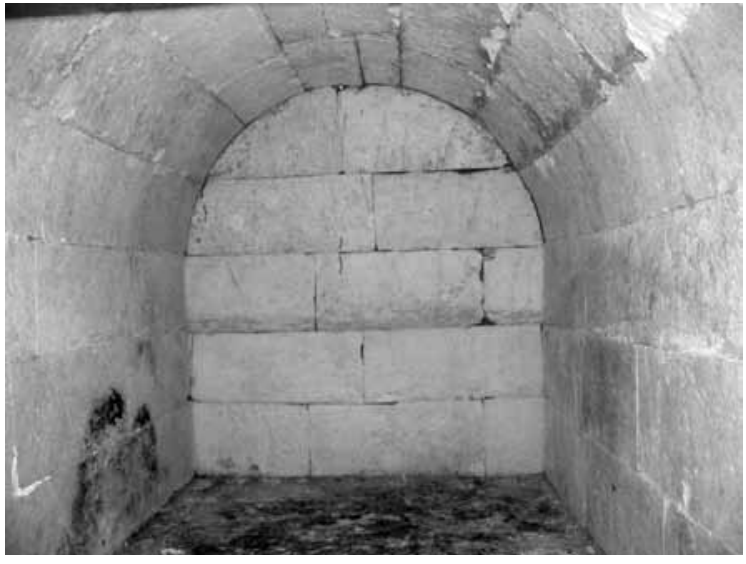

Figura 5. Interior de la cámara $n^{\circ} 6$ con el ajuar funerario

truida con bloques de piedra caliza de aspecto rectangular muy similares a las cámaras $\mathrm{n}^{\circ} 5 \mathrm{y}$ 6, y que debió de ser también aboveda, según muestra no sólo el arranque de algunas de las filas de bloques de piedra que configuran las paredes norte y sur, sino, sobre todo, la pared oeste, que se encontró intacta.

En el interior, se halló un sarcófago antropomorfo masculino de piedra caliza, epigráfico, y cuya belleza y excelente factura, hacen que éste sea el mejor y más importante de los encontrados en esta tumba. Estaba dispuesto en dirección norte-sur.

La tapa de este sarcófago, que había sido levantada por los saqueadores, tiene una inscripción jeroglífica incisa, enmarcada por líneas verticales [ 184 ] paralelas, que cubren por completo su superficie, mientras que los rasgos faciales presentan un estilo propio de la época saíta (fig. 6).

En cuanto a la caja, también presenta una inscripción jeroglífica que la rodea, y que a su vez está inscrita en dos líneas horizontales.
El estudio de estos textos nos ha proporcionado una importantísima información puesto que nos confirma la relación existente entre el propietario de la cámara $n^{\circ} 6$, y el de dicho sarcófago. Las inscripciones nos hablan de un personaje denominado Padineith, ya mencionado en cuatro de los vasos canopos descubiertos en la habitación $n^{\circ} 6$, que era hijo de una mujer llamada Tadiher, es decir, era hijo de la titular de esta misma habitación. También nos dice que era hijo de un tal Uah-ib-Rê $\hat{e}^{10}$, cuyo nombre nos apareció inscrito en un vaso canopo de alabastro en la campaña del 2002, y que formaba parte de la titulación de dos faraones de la Dinastía XXVI, Psamético y Apries. En el texto jeroglífico también podemos leer, en dos ocasiones, el nombre de la antigua ciudad de Oxirrinco, Per-Medyed. Nombre que también nos aparece en las inscripciones de las paredes de la cámara $n^{\circ} 3$ de la tumba $\mathrm{n}^{\mathrm{o}} 1$, cuyo constructor es un noble y sacerdote denominado Het, y que al igual que la tumba $\mathrm{n}^{\circ} 14$, es una tumba de tipo familiar.

En el interior del sarcófago de Padineith, no sólo se halló su cuerpo momificado, muy deteriorado y fragmentado, sino también abundantes cuentas y canutillos de collar de fayenza, en color azul, verde y blanquecino, así como diversos amuletos de piedra como un pilar-djed de cornalina, un lazo de Isis de piedra color rojo oscuro, y una figura femenina en actitud de andar de color azul, y otros tantos de oro: un udjat de $1 \mathrm{~cm}$ de altura, un ureus de $1.3 \mathrm{~cm}$ de altura, una pluma de $1.1 \mathrm{~cm}$ de altura, dos hojas de oro con decoración incisa de lazo de $1.3 \mathrm{~cm}$ de altura y una hoja con la representación incisa de Horus-halcón de $1.4 \mathrm{~cm}$ de altura, así como pequeños fragmentos de láminas de oro.

El sarcófago de Padineith, depositado sobre un pavimento de losas de piedra - hoy arrasado en parte-, estaba situado en un nivel más bajo que los

9. Esta habitación formaba parte de la $n^{\circ} 7$, hallada tres años antes.

10. Este nombre también nos parece en un sarcófago hallado en la sala 7 de la habitación $n^{\circ} 1$ de esta necrópolis saíta. 


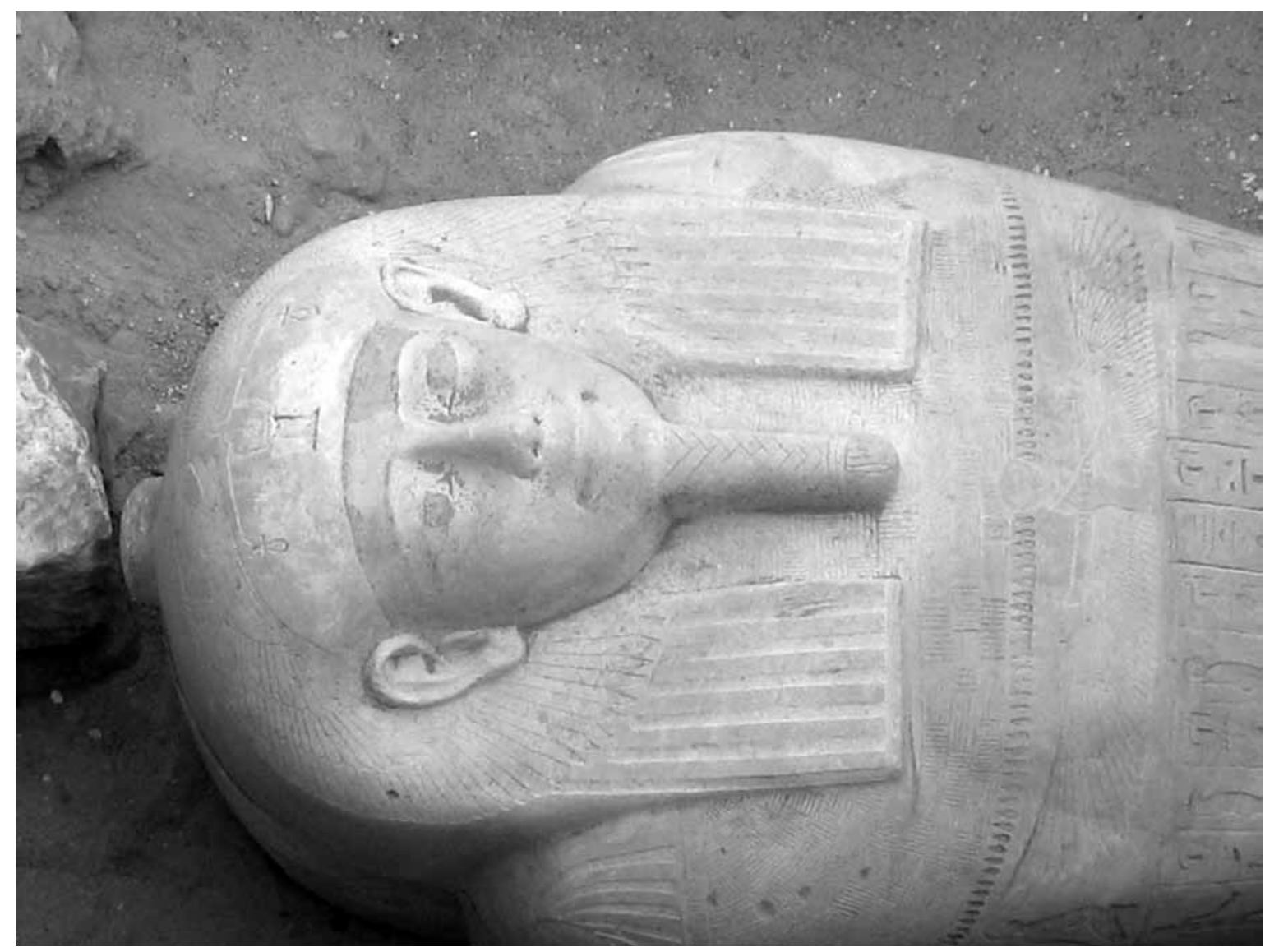

Figura 6. Sarcófago antropomorfo de época saita de Padineith

otros dos sarcófagos (20992-93, 20995-20996) hallados el año pasado en esta misma habitación ${ }^{11}$, lo que nos hace suponer que el primero fue tapado con losas de piedra, aunque en la actualidad se han perdido.

El acceso a las cámaras $n^{\circ} 5$ y 6 , se hacía a través de la $\mathrm{n}^{0} 7$, quedando ambas a la derecha de dicha habitación. Cada una de las tres estaba cubierta con su respectiva bóveda de cañón.

Por otro lado, en la zona de Oxirrinco no se han encontrado canteras de piedra caliza con la que los constructores pudieron levantar esta importante necrópolis, y en consecuencia esta tumba. Los estudios geológicos llevados a cabo en la zona de Minia, nos permiten deducir que muy probablemente el origen de los bloques de piedra estuviese en las canteras de esta localidad, las cuales abastecieron a toda su área de influencia para la construcción de tumbas en el Periodo Saíta.

Todavía queda por realizar un estudio completo de la tumba $n^{\circ} 14$ (fig. 7), ya que hasta esta última campaña del año 2006 no hemos podido delimitar todo su contorno. No obstante, ya podemos afirmar que los antiguos egipcios excavaron en esta zona una gran fosa -igual que hicieron para construir el resto de la necrópolis saíta-y que, a pesar de que ya no se conserva, es

11. Ambos sarcófagos, pertenecientes a un hombre y a una mujer estaban situados también sobre un pavimento con losas de piedra. 


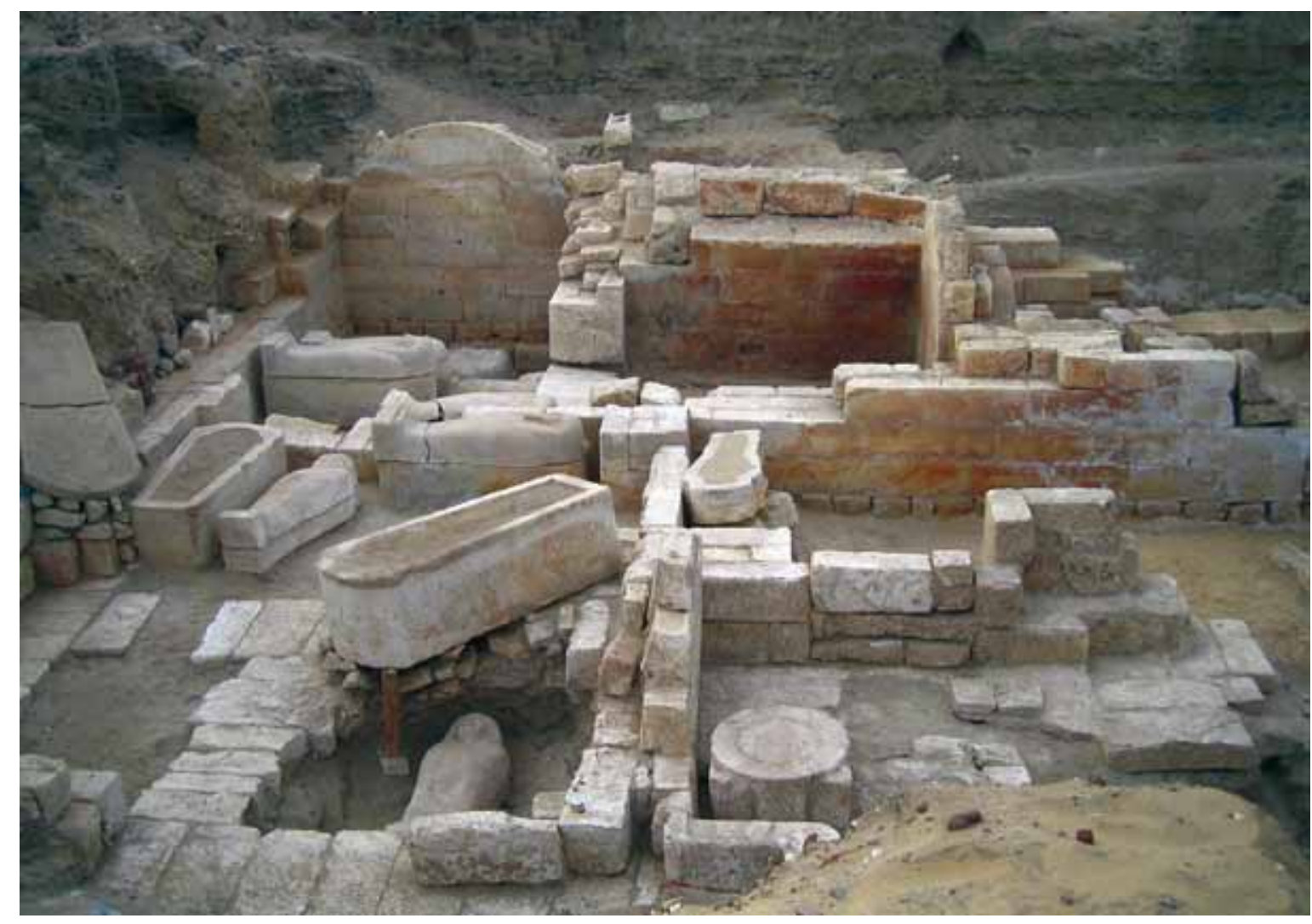

Figura 7. Vista general de la tumba $n^{\circ} 14$

muy posible que tuviera un muro de adobe que cerrase todo el complejo, como sucede en otras necrópolis del mismo periodo.

El derrumbe y colapso de dicha tumba pudo deberse con toda probabilidad tanto a causas naturales como a la acción del hombre, muy especialmente por la necesidad de acopiarse de una tipo de construcción y, por supuesto, para saquear los numerosos objetos que formaban parte del ajuar funerario de las personas allí enterradas.

El estudio completo de la tumba $\mathrm{n}^{\mathrm{o}} 14$, una vez hayamos podido delimitar ésta, nos dará sin duda alguna muchos más datos concretos, que esperamos puedan salir a la luz en un futuro próximo. 


\section{Bibliografía}

BRECCIA, E.

1940 Egitto Greco e Romano. Napoli.

DASBIRSHIRE, D.V.

1908 The Oxyrhynchus Papyri. London.

Denon, V.

1802 Voyage dans la Basse et la Haute Égypte, pendant les campagnes du général Bonaparte. Paris.

PADRÓ, J.

2004 Resumen de los trabajos arqueológicos y de restauración llevados a cabo por la Misión Arqueológica de Oxirrinco 1992-2002 (Minia Egipto), Bienes Culturales. Revista del Instituto del Patrimonio Histórico Español. Excavaciones Arqueológicas en el exterior 3: 111-118.

PADRÓ, J., ET ALII

1993a Informe preliminar sobre la campanya d'excavacions de 1992 al jaciment d' Oxirrinc (El Bahanasa, provincia de Minia), Nilus 2: 5-15. 1993b Excavaciones Arqueológicas en Oxirrinco, Egipto, Revista de Arqueología 146: 14-19.

1996 Excavacions arqueològiques a Oxirrinc (El Bahnasa, Egypte), Tribuna d'Arqueologia, 1994-1995: 167-168.

2002 Campaña 2001-2002 en Oxirrinco (ElBahnasa, Egipto), Aula Orientalis: 147161.

2004 Darreres intervencions al Jaciment d'Oxirrinc (El Bahnasa, Egypte), Tribuna d'Arqueologia, 2000-2001: 331349.

2005 El món religiós d'Oxirrinc a la llum de les darreres excavacions a El Bahnasa, província de Minia, Egipte, Tribuna d'Arqueologia, 2002-2003: 183-202.

Petrie, W.M.F.

1925 Tombs of the Courtiers and Oxyrhynchos. London.

Revees, N.

2001 Antiguo Egipto. Los grandes descubrimientos. Barcelona. 


\section{Trabajos de Egiptología Papers on Ancient Egypt}

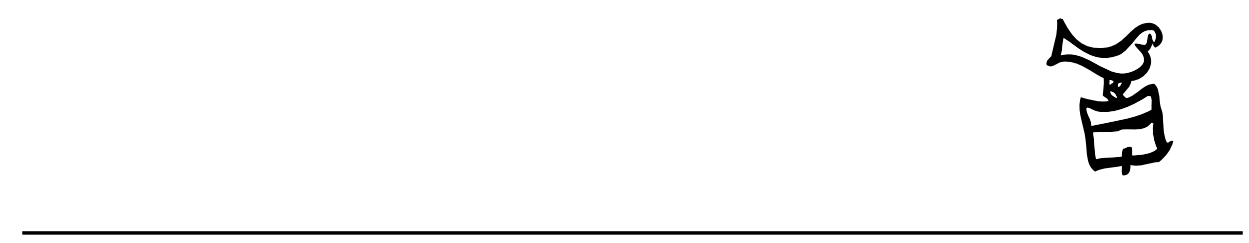

Número 5/2 2009 


\section{Actas \\ III Congreso Ibérico de Egiptología III Congresso Ibérico de Egiptologia}

Editores

Miguel Ángel Molinero Polo Covadonga Sevilla Cueva 


\title{
Editor
}

Miguel Ángel Molinero Polo

Universidad de La Laguna

\section{Consejo Editorial}

\author{
Antonio Pérez Largacha \\ Universidad de Castilla-La Mancha \\ José-R. Pérez-Accino \\ Birkbeck, Universidad de Londres \\ Covadonga Sevilla Cueva \\ Universidad Autónoma de Madrid
}

\section{Comité Científico}

Josep Cervelló i Autuori

Universitat Autònoma de Barcelona

$\mathrm{M}^{\mathrm{a}}$ José lópez Grande

Universidad Autónoma de Madrid

Josep Padró i Parcerisa

Universitat de Barcelona

$\mathrm{M}^{\mathrm{a}}$ Carmen Pérez Die

Museo Arqueológico Nacional, Madrid

Ester Pons Mellado

Museo Arqueológico Nacional, Madrid

José M. Serrano Delgado

Universidad de Sevilla

\section{Colaboradores Editoriales}

Linda Steynor

English editorial assistant

Hervé Mouriacoux

Assistant éditorial pour la langue française 
Trabajos de Egiptología está producida por Isfet. Egiptología e Historia c/ Blanco $1,2^{\circ}$

38400 Puerto de la Cruz

Tenerife-Islas Canarias

España

Maquetación: Proyecto Limón

(C) Autores de los artículos aparecidos

y Consejo Editorial de Trabajos de Egiptología - Papers on ancient Egypt

Depósito Legal: TF-2303-2009

ISSN: $1695-4750$

Imprime: Gráfica Los Majuelos, S.L.L.

imprenta@graficaslosmajuelos.com

Tfno.: 922311455 


\section{Comité Científico \\ III Congreso Ibérico de Egiptología III Congresso Ibérico de Egiptologia}

Miguel Á. Molinero Polo

Universidad de La Laguna

Presidente del Comité Organizador del III Congreso Ibérico de Egiptología

Miembro del Comité Organizador del I Encuentro de Egiptología

Josep Cervelló Autuori

Universitat Autònoma de Barcelona

Presidente del Comité Organizador del II Congreso Ibérico de Egiptologia

José Manuel Galán Allué

Consejo Superior de Investigaciones Cientificas

Director del Proyecto Djehuty, Luxor, Egipto

$\mathrm{M}^{\mathrm{a}}$ Helena Trindade Lopes

Universidad de Lisboa

Directora de la Misión Arqueológica Portuguesa en Menfis

Josep Padró i Parcerisa

Universitat de Barcelona

Director de la Misión Arqueológica de Oxirrinco

Antonio Pérez Largacha

Universidad de Castilla - La Mancha

Miembro del Comité Organizador del I Encuentro de Egiptología

José Ramón Pérez-Accino

Birkbeck College, University of London

Miembro del Comité Organizador del I Encuentro de Egiptología

$\mathrm{M}^{\mathrm{a}}$. Carmen Pérez Díe

Museo Arqueológico Nacional

Directora de la Misión Arqueológica Española en Heracleópolis Magna, Egipto

Covadonga Sevilla Cueva

Universidad Autónoma de Madrid

Miembro del Comité Organizador del I Encuentro de Egiptología 